\title{
Increased non-melanoma skin cancer risk in young patients with inflammatory bowel disease on immunomodulatory therapy: a retrospective single-centre cohort study
}

\author{
J. Clowry, ${ }^{1, *}$ J. Sheridan, ${ }^{2}$ R. Healy, ${ }^{3}$ S. Deady, ${ }^{4}$ D. Keegan, ${ }^{2}$ K. Byrne,${ }^{2}$ G. Cullen, ${ }^{2}$ H. Mulcahy, ${ }^{2}$ \\ H. Comber, ${ }^{4}$ A.C. Parnell, ${ }^{3}$ G. Doherty, ${ }^{2}$ A. Lally ${ }^{1}$ \\ ${ }^{1}$ Department of Dermatology, St Vincent's University Hospital, Dublin 4, Ireland \\ ${ }^{2}$ Department of Gastroenterology, St Vincent's University Hospital, Dublin 4, Ireland \\ ${ }^{3}$ School of Mathematics and Statistics, University College Dublin, Dublin 4, Ireland \\ ${ }^{4}$ National Cancer Registry of Ireland, Cork, Ireland \\ ${ }^{\star}$ Correspondence: J. Clowry. E-mail: julianneclowry@gmail.com
}

\begin{abstract}
Background Recent studies report an increased risk of non-melanoma skin cancer (NMSC) in immunosuppressed patients with inflammatory bowel disease (IBD). Concurrently, paediatric IBD incidence is rising, with more patients now exposed to immunomodulators from a younger age.

Objectives To investigate NMSC incidence and to examine the risk associated with immunomodulators in the development of NMSC in patients with IBD.

Methods This was a retrospective single-centre cohort study. Patients with IBD attending a tertiary adult hospital from 1994 to 2013 were included. Skin cancer incidence was compared with population data from the National Cancer Registry of Ireland (NCRI) to calculate standardized incidence ratio (SIR). Logistic regression was utilized for risk factor analysis.

Results Two thousand and fifty-three patients with IBD were studied. The SIR for NMSC in patients with IBD taking immunomodulators overall was 1.8 (95\% Cl: 1.0-2.7) with age-specific rates significantly elevated across certain age categories. Exposure to thiopurines (OR: 5.26, 95\% Cl: 2.15-12.93, $P<0.001$ ) and in particular thiopurines and/or tumour necrosis factor alpha (TNF- $\alpha$ ) inhibitors (OR: 6.45, 95\% Cl: 2.69-15.95, $P<0.001$ ) was significantly associated with NMSC. The majority (82\%) of those exposed to a TNF- $\alpha$ inhibitor also had thiopurine exposure.

Conclusions Compliance with skin cancer preventative measures should be highlighted to all patients with IBD. There should be a low threshold for dermatology referral for immunosuppressed patients, particularly those with a history of exposure to dual immunomodulators from a young age.
\end{abstract}

Received: 18 July 2016; Accepted: 14 December 2016

\section{Conflicts of interest}

None declared.

Funding sources

None declared.

\section{Introduction}

Non-melanoma skin cancer (NMSC) is the commonest malignancy in white populations, and its incidence is increasing worldwide. ${ }^{1}$ Reporting practices vary internationally; however within Europe, Ireland has the highest documented incidence of NMSC (149/ 100000 person-years) amounting to over 6800 cases annually. ${ }^{2}$

Inflammatory bowel disease affects an estimated 20000 people in Ireland. ${ }^{3}$ Thiopurines and tumour necrosis factor alpha inhibitors are the two most commonly prescribed medication classes after aminosalicylates. Earlier initiation and increasing use of these immunosuppressive agents for prolonged periods has raised concerns regarding the long-term potential association with malignancy. This is of particular relevance given the rising incidence of IBD described internationally amongst children $<16$ years old. ${ }^{4}$ In Ireland, these rates have more than doubled from 2.5/100 000/year in 2001 to 5.6 in $2010 .^{5}$

It is well recognized that the risk of NMSC is increased in immunosuppressed patients. ${ }^{6-8}$ This is most evident amongst transplant recipients, in whom squamous cell carcinomas (SCCs) occur 65-250 times as frequently as in the general 
population and basal cell carcinomas (BCCs) are increased by a factor of 10. The risk of melanoma is also increased but to a lesser degree (up to eightfold). ${ }^{9,10}$ Recent epidemiological studies support the theory that patients with IBD are also more likely to develop NMSC. ${ }^{11-15}$ Although the incidence of skin cancers in IBD is increased by immunomodulators, the absolute numbers, when compared to transplant recipients, are low. ${ }^{16,17}$ The higher incidence of NMSC in IBD has been attributed to both inherent immune dysregulation and exposure to immunosuppressive agents, particularly thiopurines. ${ }^{15,18}$ Ongoing and past exposure to thiopurines appears to significantly increase the risk of NMSC in patients with IBD even before the age of 50 years. ${ }^{15}$

Tumour necrosis factor alpha inhibitors in IBD are also associated with NMSC, ${ }^{19,20}$ but there are less conclusive data in this area. Strong evidence now supports the use of combined infliximab and azathioprine in moderate-to-severe $\mathrm{CD}^{21}$ and $\mathrm{UC}$, ${ }^{22}$ potentially placing this cohort at greater risk due to dual immunosuppression.

\section{Objectives}

The aims of this study were to compare the incidence of NMSC in both immunosuppressed and non-immunosuppressed patients with IBD, with the general population, and to investigate the risk associated with immunomodulators in the development of NMSC in patients with IBD.

\section{Materials and methods}

\section{Participants and eligibility criteria}

This was a retrospective single-centre cohort study. Approval was obtained from the hospital ethics committee. Patients were identified from a computerized IBD database of patients attending a tertiary referral adult hospital. Recorded patient demographics included date of birth, sex, smoking status, IBD subtype, date of IBD diagnosis and immunosuppressive medication exposure. The database did not specify the dose or duration of treatment with each immunomodulator. Diagnosis of IBD was confirmed by standard clinical, radiologic, endoscopic and histologic criteria. ${ }^{23}$

The IBD database was cross-referenced with the National Cancer Registry of Ireland (NCRI) records of NMSC. Registration has covered the population of Ireland since 1994 and the NCRI aims for complete ascertainment of all cases of NMSC. ${ }^{24}$ Ninety-five per cent of BCC and 98\% of SCC are histologically verified. $^{2}$ Patients were matched to the NCRI database in midAugust 2013. All skin cancers diagnosed from January 1994 to mid-2013 (and registered on the database) were included. NMSC was defined as any invasive skin cancer (ICD 10; code C44.0-C44.9) excluding melanoma (C43.0-C43.9). BCCs were defined as skin cancers with morphology M-8090-M-8110, and SCCs as skin cancers with morphology M-8070-M-8084, behaviour code 3 (invasive). ${ }^{2}$

\section{Exclusion criteria}

Patients were excluded if their IBD diagnosis preceded 1994, as skin cancer incidence data were not available prior to this date, if they were known solid organ transplant recipients or greater than 85 years old. Patients with an incomplete dataset were also excluded from the final analysis. Incident NMSCs only were included. Based on these criteria, 2053 of 3183 patients in total were eligible (Fig. 1).

\section{Statistical methods}

The first of each NMSC subtype per patient only was recorded in our results. The patients' study entry date corresponded with their date of IBD diagnosis. The study end date was the last date matched to the NCRI database (19 August 2013).

Standardized incidence ratios (SIRs) were calculated by dividing the observed numbers of cancers in the IBD cohort by the expected number. Expected cases were calculated from the product of the average national age and gender-specific incidence rates for 1994-2013 and the number of person-years at risk. SIRs for SCC and BCC were combined due to the low individual incidence figures in our cohort.

Logistic regression analysis was used to determine factors affecting the probability of IBD patients developing NMSC using the $\mathrm{R}$ function generalized linear model. ${ }^{25}$ The explanatory variables specified were age as of 19 August 2013, gender, IBD subtype and exposure to immunomodulators including thiopurines (azathioprine and 6 mercaptopurine) and TNF- $\alpha$ inhibitors (adalimumab, infliximab and certolizumab pegol). Time since IBD diagnosis was included as an offset in the model to account for varying disease duration. Significance was confirmed using both $P$-value analysis and model selection via stepwise Akaike Information Criterion (AIC) model selection. ${ }^{25}$ Statistical significance was assumed for $P$-values $<0.05$. The models examined the association of immunomodulator exposure with NMSC. The first model included thiopurines (azathioprine and 6-mercaptopurine), and the second model included patients exposed to thiopurines and TNF- $\alpha$ inhibitors. Only $3 \% \quad(n=41)$ of immunosuppressed patients had been exposed to TNF- $\alpha$ inhibitors alone, and therefore, further analysis of this subgroup was not undertaken.

More patients were exposed to azathioprine $(n=850,41 \%)$ compared to any other immunosuppressive drug in this study. Further analysis of the SIR for azathioprine was subsequently calculated specifically by age and gender using a generalized linear model (Appendix 1). Due to the low overall incidence of NMSC in the cohort, even small fluctuations in observed skin cancers in age groups of close proximity would have resulted in erratic-appearing SIRs. Poisson regression model analysis was therefore used, which borrows strength between categories and is superior to treating categories separately. ${ }^{25}$ The dependent variable for the Poisson regression was observed counts of skin cancer. Explanatory variables were age, gender and azathioprine 


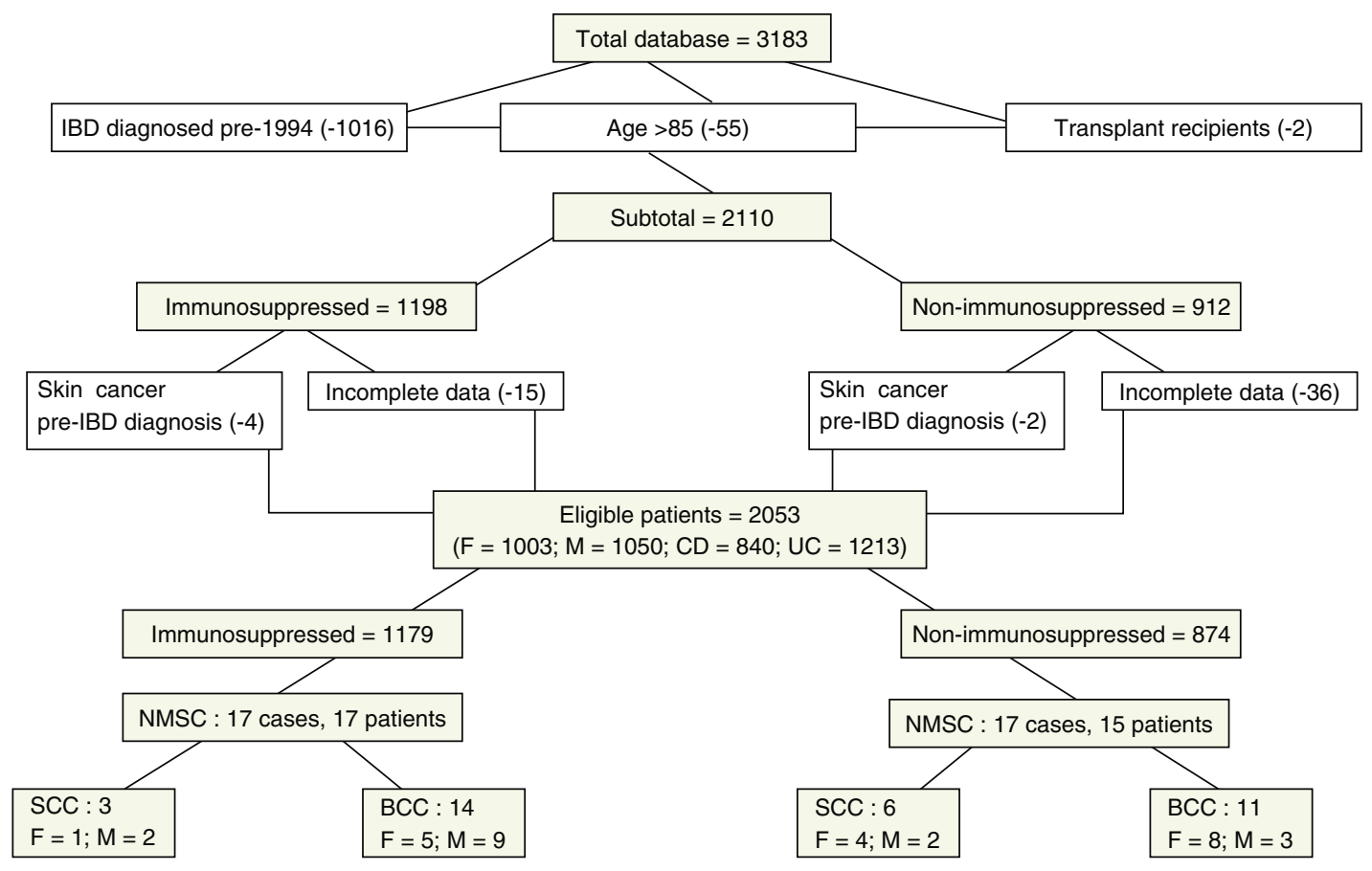

Figure 1 Patients recruited to study. BCC, basal cell carcinoma; CD, Crohn's disease; F, female; IBD, inflammatory bowel disease; M, male; NMSC, non-melanoma skin cancer; UC, ulcerative colitis; SCC, squamous cell carcinoma.

exposure. The natural $\log (\ln )$ of patient years was used as an offset so that the model reflected the rate of observed skin cancer relative to patient years. Expected values were based on the NCRI data, with the relevant incidence rate of each age category applied to the number of patient years, to provide an expected incidence for each age category. The SIR rate was calculated as the fitted values from the Poisson regression model divided by these expected values.

\section{Results}

\section{Demographics}

There were 3183 patients in the IBD database. Following the application of all exclusion criteria, 2053 were included in the final analysis (Fig. 1). The study population characteristics are outlined in Table 1. Eight hundred and forty patients (41\%) had Crohn's disease (CD) and 1213 (59\%) had ulcerative colitis (UC). Median age at IBD diagnosis was 31.1 years (range 2.4-80.6 years) and median duration of illness per patient was 9.8 years (range 1 month-19.6 years) with over 20000 person-years of follow-up. There were 1179 (57\%) patients who had been exposed to immunosuppressive medication and $874(43 \%)$ who had not. Of the immunosuppressed cohort, $92 \%$ had been exposed to a thiopurine and $44 \%$ to a TNF- $\alpha$ inhibitor. Eighty-two per cent of patients on TNF- $\alpha$ inhibitors had also been exposed to thiopurines.
Patients with IBD who were immunosuppressed were more likely to be younger $(P<0.001)$ and to have a diagnosis of $\mathrm{CD}$ rather than $\mathrm{UC}(P<0.001)$.

\section{Skin cancer}

There were 34 incident cases of NMSC ( $1.7 \%$ of total cohort), 17 in both the immunosuppressed and non-immunosuppressed groups (Table 2). Nine patients had an SCC, 25 had a BCC and two patients had both an SCC and BCC. All immunosuppressed patients with NMSC had thiopurine (specifically azathioprine) exposure. Six patients (35\%) had also been exposed to TNF- $\alpha$ inhibitor. The mean age at NMSC diagnosis was 54.1 years (SD 12.7 years), and the mean IBD duration at time of diagnosis was 7.5 years (SD 5.4 years).

\section{Standardized incidence ratios}

The SIR for NMSC in all patients with IBD (i) both immunosuppressed and non-immunosuppressed, (ii) immunosuppressed only, (iii) non-immunosuppressed only and (iv) exposed to thiopurines only is outlined in Table 3. These results demonstrate that NMSC is more common in all of these groups than in the general population. This increased risk of NMSC approaches statistical significance in the entire group of patients with IBD (SIR 1.3, 95\% CI: 0.9-1.8).

The graphs in Figs 2 and 3 show the age-related variation in the SIRs for NMSC amongst males and females exposed to 
Table 1 Patient characteristics and drug exposure

\begin{tabular}{|c|c|c|c|c|}
\hline & $\begin{array}{l}\text { All patients } \\
(n=2053)\end{array}$ & $\begin{array}{l}\text { Immunosuppressed } \\
\text { patients }(n=1179)\end{array}$ & $\begin{array}{l}\text { Non-immunosuppressed } \\
(n=874)\end{array}$ & $P$-value \\
\hline \multicolumn{5}{|l|}{ Gender } \\
\hline Male & $1050(51 \%)$ & $619(53 \%)$ & $431(49 \%)$ & 0.15 \\
\hline Female & $1003(49 \%)$ & $560(47 \%)$ & $443(51 \%)$ & \\
\hline \multicolumn{5}{|l|}{ IBD subtype, $n(\%)$} \\
\hline Crohn's & $840(41 \%)$ & $577(49 \%)$ & $263(30 \%)$ & $<0.001$ \\
\hline Ulcerative colitis & $1213(59 \%)$ & $602(51 \%)$ & $611(70 \%)$ & \\
\hline Median age at diagnosis with IBD (range) & $\begin{array}{l}31.1 \text { years } \\
(2.4-80.6 \text { years })\end{array}$ & $\begin{array}{l}29.1 \text { years } \\
(6.5-77.6 \text { years })\end{array}$ & $\begin{array}{l}33.7 \text { years } \\
(2.4-80.6 \text { years })\end{array}$ & $<0.001$ \\
\hline Median duration of illness (range) & $\begin{array}{l}9.8 \text { years } \\
(1 \text { month-19.6 years })\end{array}$ & $\begin{array}{l}9.7 \text { years } \\
\text { ( } 1 \text { month-19.6 years) }\end{array}$ & $\begin{array}{l}10.2 \text { years } \\
(1 \text { month-19.6 years })\end{array}$ & 0.36 \\
\hline Median age at end of study (range) & $\begin{array}{l}41.4 \text { years } \\
(16.5-84.5 \text { years })\end{array}$ & $\begin{array}{l}39.0 \text { years } \\
(17.0-84.4 \text { years })\end{array}$ & $\begin{array}{l}44.5 \text { years } \\
(16.5-84.5 \text { years })\end{array}$ & $<0.001$ \\
\hline \multicolumn{5}{|l|}{ Drug exposure } \\
\hline Thiopurine, $n(\%)$ & $1084(53 \%)$ & $1084(92 \%)$ & $0(0 \%)$ & \\
\hline AZA total, $n(\%)$ & $850(41 \%)$ & $850(72 \%)$ & $0(0 \%)$ & \\
\hline AZA only, $n(\%)$ & $748(36 \%)$ & $748(63 \%)$ & $0(0 \%)$ & \\
\hline $6 \mathrm{MP}$ total, $n(\%)$ & $149(7 \%)$ & $149(13 \%)$ & $0(0 \%)$ & \\
\hline 6MP only, $n(\%)$ & $47(2 \%)$ & $47(3 \%)$ & $0(0 \%)$ & \\
\hline AZA \& 6MP, $n(\%)$ & $102(5 \%)$ & $102(9 \%)$ & $0(0 \%)$ & \\
\hline Thiopurine unspecified, $n(\%)$ & $187(9 \%)$ & $187(16 \%)$ & $0(0 \%)$ & \\
\hline TNF- $\alpha$ inhibitors total, $n(\%)$ & $513(25 \%)$ & $513(44 \%)$ & $0(0 \%)$ & \\
\hline TNF- $\alpha$ inhibitors only, $n(\%)$ & $41(2 \%)$ & $41(3 \%)$ & $0(0 \%)$ & \\
\hline Both thiopurine and TNF- $\alpha$ inhibitors, $n(\%)$ & $421(21 \%)$ & $421(36 \%)$ & $0(\%)$ & \\
\hline Both azathioprine and TNF- $\alpha$ inhibitors, $n(\%)$ & $385(19 \%)$ & $385(33 \%)$ & $0(0 \%)$ & \\
\hline \multicolumn{5}{|l|}{ Smoker at diagnosis } \\
\hline No & $1037(50 \%)$ & $617(52 \%)$ & $420(48 \%)$ & \\
\hline Yes & $387(19 \%)$ & $238(20 \%)$ & $149(17 \%)$ & \\
\hline Ex-smoker & $326(16 \%)$ & $185(16 \%)$ & $141(16 \%)$ & \\
\hline Unknown & $303(15 \%)$ & $139(12 \%)$ & $164(19 \%)$ & \\
\hline
\end{tabular}

AZA, azathioprine; IBD, inflammatory bowel disease; $6 \mathrm{MP}, 6$ mercaptopurine; $n$, number; TNF- $\alpha$ inhibitors, tumour necrosis factor alpha inhibitors.

Table 2 Non-melanoma skin cancer distribution

\begin{tabular}{lllllll}
\hline & $\begin{array}{l}\text { All patients } \\
(\boldsymbol{n}=\mathbf{2 0 5 3 )}\end{array}$ & $\begin{array}{l}\text { Immuno } \\
\text { suppressed } \\
\text { patients } \\
(\boldsymbol{n}=\mathbf{1 1 7 9 )}\end{array}$ & $\begin{array}{l}\text { Non- } \\
\text { immuno } \\
\text { suppressed } \\
(\boldsymbol{n}=\mathbf{8 7 4 )}\end{array}$ & $\begin{array}{l}\text { Exposed to } \\
\text { thiopurine } \\
(\boldsymbol{n}=1084)\end{array}$ & $\begin{array}{l}\text { Not exposed to } \\
\text { thiopurine } \\
(\boldsymbol{n}=\mathbf{9 6 9 )}\end{array}$ & $\begin{array}{l}\text { TNF exp } \\
(\boldsymbol{n}=\mathbf{5 1 3})\end{array}$ \\
\hline SCC only & $7(0.3 \%)$ & $3(0.3 \%)$ & $4(0.5 \%)$ & $3(0.3 \%)$ & $4(0.4 \%)$ & $2(0.4 \%)$ \\
BCC only & $25(1.2 \%)$ & $14(1.2 \%)$ & $11(1.3 \%)$ & $14(1.3 \%)$ & $11(1.1 \%)$ & $4(0.8 \%)$ \\
SCC \& BCC & $2(0.1 \%)$ & 0 & $2(0.2 \%)$ & 0 & $2(0.2 \%)$ & 0 \\
Total NMSC & $34(1.7 \%)$ & $17(1.4 \%)$ & $17(1.9 \%)$ & $17(1.6 \%)$ & $17(1.8 \%)$ & $6(1.2 \%)$ \\
\hline
\end{tabular}

BCC, basal cell carcinoma; $n$, number; NMSC, non-melanoma skin cancer; SCC, squamous cell carcinoma.

azathioprine. This exposure appears to have greatest effect from age 30-50 and also in the over 70s; however, it should also be noted that the confidence intervals are wide. The SIR appears higher in males as compared to females, particularly up to age 45-50, but again wide confidence intervals are present.

\section{Logistic regression analysis}

Thiopurine exposure (Table 4, i) was significantly associated with a risk of developing NMSC and had an odds ratio of
5.26 (95\% CI: 2.15-12.93, $P<0.001$ ). Patients exposed to both thiopurines and TNF- $\alpha$ inhibitors (Table 4, ii), however, had the highest odds ratio of 6.45 (95\% CI: 2.69-15.95, $P<0.001)$. Notably, $82 \%$ of patients who had exposure to TNF- $\alpha$ inhibitors also had thiopurine exposure. Only 41 patients had been exposed to TNF- $\alpha$ inhibitors alone, and therefore, no significant association with NMSC could be determined. Ageing was a significant risk factor across all categories of immunosuppression. Gender, smoking history and 
Table 3 Standardized incidence ratios for non-melanoma skin cancer in comparison with the general population

\begin{tabular}{|c|c|c|c|c|}
\hline & All IBD & $\begin{array}{l}\text { Non- } \\
\text { immunosuppressed }\end{array}$ & $\begin{array}{l}\text { All } \\
\text { immunosuppressed }\end{array}$ & Thiopurines \\
\hline SIR & 1.3 & 1.07 & 1.76 & 1.8 \\
\hline $95 \%$ Confidence interval & $0.9-1.8$ & $0.6-1.6$ & $1.0-2.7$ & $1.0-2.8$ \\
\hline
\end{tabular}

IBD, inflammatory bowel disease; SIR, standardized incidence ratio.

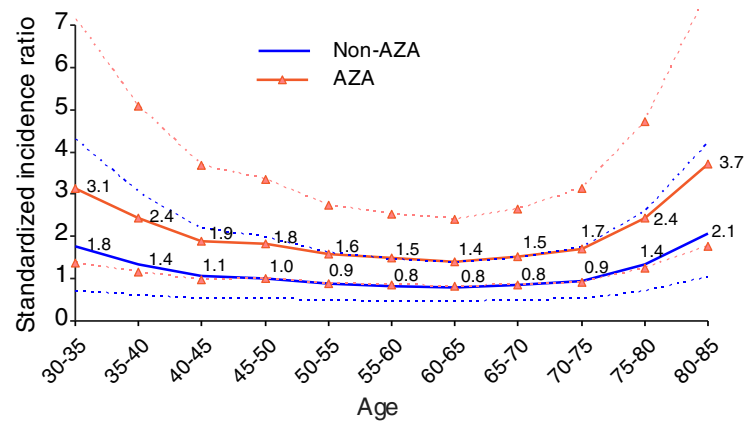

Figure 2 Standardized incidence ratio of non-melanoma skin cancer in male patients with inflammatory bowel disease in relation to azathioprine exposure (dotted lines represent confidence intervals). AZA, azathioprine; non-AZA, not exposed to azathioprine or other immunosuppression.

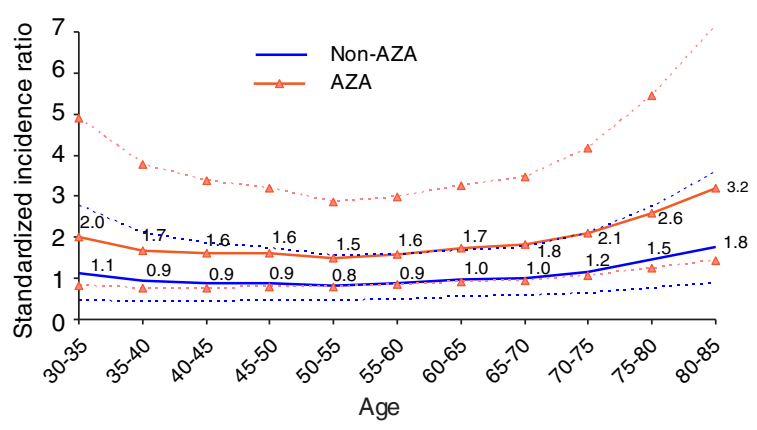

Figure 3 Standardized incidence ratio of non-melanoma skin cancer in female patients with inflammatory bowel disease in relation to azathioprine exposure (dotted lines represent confidence intervals). AZA, azathioprine; non-AZA, not exposed to azathioprine or other immunosuppression.

IBD subtypes were not associated with NMSC risk in any models.

\section{Discussion}

This retrospective single-centre cohort study of patients with IBD examines NMSC incidence spanning almost 20 years from 1994 until mid-2013. The incidence of NMSC was $1.7 \%$ in the total cohort $(n=34 / 2053), 1.4 \%$ in immunosuppressed patients $(n=17 / 1179)$ and $1.9 \%$ in non-
Table 4 Final logistic regression analysis for (i) model including thiopurine exposure and (ii) model including exposure to thiopurine and/or tumour necrosis factor alpha inhibitors

\begin{tabular}{lllll}
\hline & Variables & $\begin{array}{l}\text { Odds } \\
\text { ratio }\end{array}$ & $95 \%$ Cl & $P$-value \\
\hline (i) & $\begin{array}{l}\text { Thiopurine exposure only } \\
\text { (not TNF- } \alpha \text { inhibitors) }\end{array}$ & 5.26 & $(2.15,12.93)$ & $<0.001$ \\
& $\begin{array}{l}\text { Age } \\
\text { (ii) } \quad \begin{array}{l}\text { Thiopurine and/or TNF- } \alpha \\
\text { inhibitor }\end{array}\end{array}$ & 1.13 & $(1.1,1.18)$ & $<0.001$ \\
\hline Age & 1.14 & $(2.69,15.95)$ & $<0.001$ \\
\hline
\end{tabular}

(i) Logistic regression analysis for model including thiopurine exposure, age, gender, smoking status and type of inflammatory bowel disease. Significant variables were thiopurine exposure and age as shown with $P$-values and odds ratios including $95 \%$ confidence interval. TNF- $\alpha=$ tumour necrosis factor alpha.

(ii) Logistic regression analysis for model including exposure to a thiopurine and/or tumour necrosis factor alpha (TNF- $\alpha$ ) inhibitors, age, gender, smoking status and type of inflammatory bowel disease. Significant variables were thiopurine exposure and age as shown with $P$-values and odds ratios (including 95\% confidence interval).

immunosuppressed patients $(n=17 / 874)$. The ratio of BCC to SCC (approaching 3:1) is similar to the general population; ${ }^{2}$ however, it must be interpreted with caution given the low case numbers.

Exposure to UV radiation is recognized as the primary cause of NMSC, ${ }^{26}$ correlating with higher NMSC incidence associated with decreasing latitudes, sun seeking behaviour and indoor tanning. Ultraviolet A (UVA) radiation and azathioprine act as synergistic mutagens ${ }^{27}$ due to the incorporation of 6 thioguanine (6 TG), the active metabolite of thiopurines, into DNA. Azathioprine is generally the first-line thiopurine used in Europe and is classified as a carcinogen by the International Agency for Research on Cancer. ${ }^{28}$ Even in temperate climates, patients are at risk, given that UVA accounts for $95 \%$ of ambient sunlight, is present year-round, can penetrate glass and to basal layer stem cells where carcinogenic changes may persist post-treatment. ${ }^{27}$ Unlike azathioprine, TNF- $\alpha$ inhibitors are not photosensitizers, but it is hypothesized that overexposure to insulin-like growth factor 1 (IGF-1), secondary to TNF- $\alpha$ inhibition, may be linked to malignancy. ${ }^{20,29,30}$

Advancing age was also identified as a significant risk factor in the development of NMSC in this study $(P<0.001)$, which may account for the higher overall skin cancer incidence in the non- 
immunosuppressed cohort. Ageing is associated with decreasing capacity to repair DNA, falling by $0.61 \%$ annually from age $20 .^{31}$ Patients with IBD and a history of exposure to immunosuppression were significantly younger (median age at end of study: 39 years; range $17-44.5$ years) than non-immunosuppressed patients (median age: 44.5 years; range 16.5-84.5 years, $P<0.001)$. National skin cancer incidence statistics corroborate these findings and show an age-related increase in melanoma and NMSC, particularly SCC, over age $65 .^{2}$

It is, however, important to note that younger IBD patients on immunomodulators had relatively higher rates of NMSC, when compared to their peers in the general population (SIR: 1.76; CI $=1-2.7$ ), whereas marginally higher SIR in the nonimmunosuppressed cohort compared to age-matched counterparts was not significant (SIR: 1.07; CI $=0.6-1.6$ ). The SIR for NMSC was also noted to be higher in males exposed to azathioprine compared to females of similar age; however given the wide confidence intervals, this data must be interpreted conservatively. Additional risk factors, e.g. greater UV exposure or perhaps lesser compliance with photoprotection, may be of more importance in this group.

Patients with IBD and a history of exposure to thiopurines and/or TNF- $\alpha$ inhibitors had the highest odds of developing NMSC (OR: 6.45; 95\% CI: 2.69-15.95, $P<0.001$ ). Notably, the majority $(82 \%)$ of those exposed to TNF- $\alpha$ inhibitors also had thiopurine exposure. Dual immunosuppressive regimens consisting of azathioprine and infliximab are superior to either agent alone in moderate-to-severe Crohn's and UC, ${ }^{21,22}$ but correspondingly also carry the greatest risk of developing NMSC according to our results. This supports intuitive reasoning that more potent immunosuppression carries the greatest risk. These findings correlate with outcomes from Mc Kenna et al. ${ }^{20}$ who demonstrated that TNF- $\alpha$ inhibitor monotherapy and combination treatment with a thiopurine were both significantly associated with NMSC $(P<0.001)$. Only 3\% $(n=41 / 1179)$ of immunosuppressed patients in our cohort had exposure to TNF- $\alpha$ inhibitors without thiopurines, and therefore, no significant association due to TNF- $\alpha$ inhibition alone could be determined.

From our results, thiopurines (azathioprine and/or 6 mercaptopurine) had an OR of 5.26 (95\% CI: 2.15-12.93, P<0.001). Accordingly, the CESAME (Cancers Et Surrisque Associé aux Maladies inflammatoires intestinales En France) observational cohort showed that ongoing thiopurine exposure (HR 5.9; 95\% CI: $2.1-16.4 P<0.0006$ ) and past exposure (HR 3.9; 95\% CI: 1.3-2.1, $P<0.02)$ significantly increased NMSC risk in patients with IBD, even before the age of $50 .{ }^{15}$

Overall, our results are of concern, given the rising number of IBD diagnoses under the age of $18,{ }^{6}$ the earlier introduction of immunomodulatory therapy and the increasing use of combination treatments. ${ }^{32}$ Due to the prevalence of NMSC, even low-level escalation can lead to a sizeable impact on caseload, morbidity and economic burden. Currently, NMSC costs approximately $€ 17$ million annually in Ireland ${ }^{2}$ and is projected to reach $£ 180$ million in the UK by 2020 . $^{33}$

Consensus opinion, however, is that immunomodulatory treatment should not be limited by these risks. ${ }^{34}$ Other studies $^{35,36}$ have failed to find conclusive associations between specific immunomodulator classes and NMSC in IBD, and therefore, a meta-analysis is warranted.

Long-term azathioprine remains the first-line immunomodulatory treatment for patients with IBD, given its efficacy and relapse rates of $65-75 \%$ off-therapy. ${ }^{37}$ Mycophenolate mofetil, which has a more favourable risk profile as regards cutaneous malignancies, is less effective with variable tolerance in $\mathrm{IBD}^{38}$ and is not currently recommended. ${ }^{38,39}$ Age, previous skin malignancy, significant UV exposure and reduced thiomethylpurine transferase (TPMT) activity should be taken into account, ${ }^{40}$ and clinical IBD guidelines ${ }^{39}$ that strongly advocate photoprotection should be reinforced. A US study recently concluded that annual screening of all patients with Crohn's disease was the most successful and cost-effective strategy for early detection of NMSC, ${ }^{41}$ but within the constraints of a public health service, regular skin screening is not always feasible.

\section{Strengths}

This is the first study examining NMSC risk in patients with IBD in an Irish population, which is situated in a relatively homogenous area as regards latitude, sun exposure and skin phototype. Irish patients are predominantly fair-skinned ${ }^{42}$ with $94 \%{ }^{43}$ selfreporting white skin type. The NCRI provides robust data on all NMSC in Ireland, giving true incidence figures for BCC and SCC. This contrasts with some international registries, which do not record certain subtypes. ${ }^{1}$ Although the study population was relatively small $(n=2053)$, the retrospective review period reviewed was almost 20 years, amounting to over 20000 patient years of data.

\section{Limitations}

The limitations include the small sample size and low incidence rate, although our NMSC case numbers are comparable to previous studies. ${ }^{15,44}$ The analysis was based on a hospital database, which may over-represent severe IBD. Only $30 \%$ of patients with IBD attend for regular hospital follow-up, ${ }^{5}$ introducing both selection and ascertainment bias. These patients generally have serious underlying disease requiring immunosuppression, more frequent follow-up and may have higher dermatology referral rates.

Duration of exposure to particular immunosuppressive treatments can be challenging to ascertain and was not recorded in this database, similar to previous studies. ${ }^{37,44}$ We did not have data on prior UV exposure, which may have revealed age- or gender-related variation, but patients were resident within a limited geographical area. Analysis of the dose-dependent effect of 
thiopurines on NMSC, adjusting for TPMT activity, was not possible, as TPMT levels were not recorded in the IBD cohort. This would be an interesting area to pursue in future studies investigating patient risk stratification.

\section{Conclusions}

This retrospective cohort study shows a small but significantly increased incidence of NMSC in immunosuppressed patients with IBD, as compared to the general population. It identifies ageing, exposure to thiopurines alone and in combination with TNF- $\alpha$ inhibitors as risk factors in the development of NMSC within this cohort. The relatively high SIRs for NMSC amongst younger immunosuppressed patients are particularly concerning given the rising incidence of IBD in the paediatric and young adult population. This trend, combined with the increasing use of dual immunomodulatory therapy for sustained periods, is likely to contribute to higher rates of NMSC amongst this cohort in future. Nevertheless, immunosuppressive treatment remains a vital component of disease management in IBD, and therefore, greater emphasis must be placed on primary preventive measures, as outlined in clinical guidelines. ${ }^{39}$ In the setting of limited healthcare resources, our results support targeted dermatology referrals for patients with IBD, particularly those exposed to dual immunomodulatory therapy from an early age.

\section{Acknowledgement}

The authors wish to acknowledge Dr Karen Eustace, who assisted with the study proposal and ethics submission.

\section{References}

1 Lomas A, Leonardi-Bee J, Bath-Hextall F. A systematic review of worldwide incidence of nonmelanoma skin cancer. Br J Dermatol 2012; 166: 1069-1080.

2 Deady S, Sharp L, Comber H. Increasing skin cancer incidence in young, affluent, urban populations: a challenge for prevention. Br J Dermatol 2014; 171: 324-331.

3 Irish Society for Colitis and Crohn's Disease. 2014. http://www.iscc.ie/ facts.

4 Benchimol EI, Fortinsky KJ, Godzdyra P et al. Epidemiology of paediatric inflammatory bowel disease: a systematic review of international trends. Inflamm Bowel Dis 2010; 17: 423-439.

5 Hope B, Shahdadpuri R, Dunne C et al. Rapid rise in incidence of Irish paediatric inflammatory bowel disease. Arch Dis Child 2012; 97: 590-594.

6 Engels EA, Pfeiffer RM, Goedert JJ et al. Trends in cancer risk among people with AIDS in the United States 1980-2002. AIDS 2006; 20: 16451654.

7 Brewer J, Haberman TM, Shanafelt TD. Lymphoma-associated skin cancer: incidence, natural history, and clinical management. Int J Dermatol 2014; 53: 267-274.

8 Moloney FJ, Comber H, O'Lorcain P, O'Kelly P, Conlon PJ, Murphy GM. A population-based study of skin cancer incidence and prevalence in renal transplant recipients. Br J Dermatol 2006; 154: 498-504.

9 Euvrard S, Kanitakis J, Claudy A. Skin cancers after organ transplantation. N Engl J Med 2003; 348: 1681-1691.

10 Le Mire L, Hollowood K, Gray D, Bordea C, Wojnarowska F. Melanomas in renal transplant recipients. Br J Dematol 2006; 154: 472-477.
11 Long MD, Herfarth HH, Pipkin CA, Porter CQ, Sandler RS, Kappelman MD. Increased risk for non-melanoma skin cancer in patients with inflammatory bowel disease. Clin Gastroenterol Hepatol 2010; 8: 268-274.

12 Pedersen N, Duricova D, Elkjaer M, Gamborg M, Munkholm P, Jess T. Risk of extra-intestinal cancer in inflammatory bowel disease: meta-analysis of population-based cohort studies. Am J Gastroenterol 2010; 105: 1480-1487.

13 Singh H, Nugent Z, Demers AA, Bernstein CN. Increased risk of nonmelanoma skin cancers among individuals with inflammatory bowel disease. Gastroenterology 2011; 141: 1612-1620.

14 Ekbom A, Helmick C, Zack M, Adami HO. Extracolonic malignancies in inflammatory bowel disease. Cancer 1991; 67: 2015-2019.

15 Peyrin-Biroulet L, Khosrotehrani K, Carrat F et al. Increased risk for nonmelanoma skin cancers in patients who receive thiopurines for inflammatory bowel disease. Gastroenterology 2011; 141: 16211628.e1-5.

16 Biancone L, Onali S, Petruzziello C, Calabrese E, Pallone F. Cancer and immunomodulators in inflammatory bowel diseases. Inflamm Bowel Dis 2015; 21: 674-698.

17 Ariyaratnam J, Subramanian V. Association between thiopurine use and nonmelanoma skin cancers in patients with inflammatory bowel disease: a meta-analysis. Am J Gastroenterol 2014; 109: 163-169.

18 Pasternak B, Svanstrom H, Schmiegelow K, Jess T, Hviid A. Use of azathioprine and the risk of cancer in inflammatory bowel disease. Am J Epidemiol 2013; 177: 1296-1305.

19 Long MD, Martin CF, Pipkin CA, Herfarth HH, Sandler RS, Kappelman MD. Risk of melanoma and nonmelanoma skin cancer among patients with inflammatory bowel disease. Gastroenterology 2012; 143: 390-399.e1.

20 McKenna MR, Stobaugh DJ, Deepak P. Melanoma and non-melanoma skin cancer in inflammatory bowel disease patients following tumor necrosis factor- $\alpha$ inhibitor monotherapy and in combination with thiopurines: analysis of the Food and Drug Administration Adverse Event Reporting System. J Gastrointestin Liver Dis 2014; 23: 267-271.

21 Colombel JF, Sandborn WJ, Reinisch W et al. Infliximab, azathioprine, or combination therapy for Crohn's disease. N Engl J Med 2010; 362: 13831395.

22 Panaccione R, Ghosh S, Middleton S et al. Combination therapy with infliximab and azathioprine is superior to monotherapy with either agent in ulcerative colitis. Gastroenterology 2014; 146: $392-$ 400.e3.

23 Lennard-Jones JE. Classification of inflammatory bowel disease. Scand J Gastroenterol Suppl 1989; 170: 2-6; discussion 16-9.

24 O’Brien K, Comber H, Sharp L. Completeness of case ascertainment at the Irish National Cancer Registry. Ir J Med Sci 2014; 183: 219224.

25 Dobson AJ, Barnett AG. An Introduction to Generalized Linear Models, 3rd edn. Chapman \& Hall/CRC, Boca Raton, FL; London, 2008.

26 Xiang F, Lucas R, Hales S, Neale R. Incidence of nonmelanoma skin cancer in relation to ambient UV radiation in white populations, 1978-2012: empirical relationships. JAMA Dermatol 2014; 150: 1063-1071.

27 O'Donovan P, Perrett CM, Zhang X et al. Azathioprine and UVA light generate mutagenic oxidative DNA damage. Science 2005; 309: 1871-1874.

28 International Agency for Research on Cancer. A Review of Human Carcinogens, Pharmaceuticals, Volume 100A. Lyon (France): International Agency for Research on Cancer; 2008.

29 Hakam A, Yeatman TJ, Lu L et al. Expression of insulin-like growth factor-1 receptor in human colorectal cancer. Hum Pathol 1999; 30: 1128-1133.

30 Turner BC, Haffty BG, Narayanan L et al. Insulin-like growth factor-I receptor overexpression mediates cellular radio resistance and local breast 
cancer recurrence after lumpectomy and radiation. Cancer Res 1997; 57: 3079-3083.

31 Wei Q, Matanoski GM, Farmer ER, Hedayati MA, Grossman L. DNA repair and aging in basal cell carcinoma: a molecular epidemiology study. Proc Natl Acad Sci USA 1993; 90: 1614-1618.

32 D'Haens G, Baert F, van Assche G et al. Early combined immunosuppression or conventional management in patients with newly diagnosed Crohn's disease: an open randomised trial. Lancet 2008; 371: 660-667.

33 Vallejo-Torres L, Morris S, Kinge JM, Poirier V, Verne J. Measuring current and future cost of skin cancer in England. J Public Health (Oxf) 2014; 36: $140-148$.

34 Kerbleski JF, Gottlieb AB. Dermatological complications and safety of anti-TNF treatments. Gut 2009; 58: 1033-1039.

35 Scott FI, Mamtani R, Brensinger CM et al. Risk of nonmelanoma skin cancer associated with the use of immunosuppressant and biologic agents in patients with a history of autoimmune disease and nonmelanoma skin cancer. JAMA Dermatol 2015; 28: 1-9.

36 Armstrong RG, West J, Card TR. Risk of cancer in inflammatory bowel disease treated with azathioprine: a UK population-based case-control study. Am J Gastroenterol 2010; 105: 1604-1609.

37 Fraser AG, Orchard TR, Jewell DP. The efficacy of azathioprine for the treatment of inflammatory bowel disease: a 30 year review. Gut 2002; 50: 485-489.

38 Renna S, Cottone M, Orlando A. Optimization of the treatment with immunosuppressants and biologics in inflammatory bowel disease. World J Gastroenterol 2014; 20: 9675-9690.

39 Mowat C, Cole A, Windsor A et al. Guidelines for the management of inflammatory bowel disease in adults. Gut 2011; 60: 571-607.

40 Algaba A, Guerra I, Marín-Jiménez I et al. Incidence, management, and course of cancer in patients with inflammatory bowel disease. J Crohns Colitis 2015; 9: 326-333.

41 Okafor PN, Stallwood CG, Nguyen L et al. Cost-effectiveness of nonmelanoma skin cancer screening in Crohn's disease patients. Inflamm Bowel Dis 2013; 19: 2787-2795.

42 Gibson GE, Codd MB, Murphy GM. Skin type distribution and skin disease in Ireland. Ir J Med Sci 1997; 166: 72-74.

43 Central Statistics Office. Census 2011. Profile 7: Religion, Ethnicity and Irish Travellers. The Stationary Office, Dublin, 2012.

44 Setshedi M, Epstein D, Winter TA, Myer L, Watermeyer G, Hift R. Use of thiopurines in the treatment of inflammatory bowel disease is associated with an increased risk of non-melanoma skin cancer in an at-risk population: a cohort study. J Gastroenterol Hepatol 2012; 27: 385-389.

45 R Core Team. R: A Language and Environment for Statistical Computing. R Foundation for Statistical Computing, Vienna, Austria, 2014. Accessed on 23 February 2015. URL http://www.R-project.org/
46 Venables WN, Ripley BD. Modern Applied Statistics with S, 4th edn. Springer, UK, 2002.

\section{Appendix 1}

A generalized linear model $(\mathrm{glm})$ is a commonly used generalization of the standard linear regression model when data are not assumed to have normally distributed errors. The $\mathrm{R}$ function $\mathrm{glm}^{45}$ fits a logistic regression model to data and produces coefficient estimates, odds ratios, standard errors and $P$-values for all specified explanatory variables.

Using the AIC approach ${ }^{46}$ different combinations of explanatory variables were used to compare fitted models. The AIC measures how closely the model fits the data, with a penalty for model complexity. The 'best' model is that deemed to have the lowest AIC. The $P$-value selection and AIC approaches (via the step AIC R function) both agreed on the same model.

A Poisson regression model ${ }^{25}$ was chosen to reduce errors accounting for the low incidence of NMSC and small fluctuations in observed cases in age groups of close proximity.

The patient data were recorded in a multiway contingency table including observed counts of skin cancer (SCC and/or $\mathrm{BCC}$ ), age group, gender, azathioprine exposure, anti-TNF exposure and all immunosuppressant exposure. Age groups were in 17 categories of 5 -year intervals from 0 to 85 years. The dependent variable for the Poisson regression was observed counts of skin cancer. Explanatory variables were age group, gender and immunosuppressant exposure. The natural $\log (\ln )$ was used as an offset so that the model reflected the rate of observed skin cancer relative to patient years. Standard model diagnostics indicated that the model provided a good fit for the data.

The relevant incidence rate was applied to the number of patient years, to provide an 'expected' incidence for each row. The SIR was calculated as the fitted values from the Poisson regression model divided by these expected values. 